\title{
Utilisation de la paille dans des rations d'engraissement : ingestion, dynamique de la digestion et cinétique de dégradabilité dans le rumen
}

\author{
AP Mayombo, C Van Eenaeme, S Gauthier, I Dufrasne, L Istasse
}

Service de Nutrition, Fac Méd Vét, Univ de Liège Sart-Tilman, 43-4000 Liège. Belgique

La paille est un aliment indispensable dans les rations d'engraissement à base de concentré. Elle a pour but de régulariser les fermentations dans le rumen et d'éviter des pathologies. Généralement, la paille est disponible dans un râtelier. Les mélangeuses distributrices permettent de mélanger de la paille hachée au concentré.

Un total de 6 taurillons BBB du type mixte munis d'une canule du rumen ont été utilisés. Ils ont été répartis en 2 groupes de 3 animaux et maintenus sur des stalles à métabolisme. Pendant la première période, le premier groupe recevait séparément le concentré d'engraissement à base de pulpes séchées $(40,8 \%)$, céréales (37\%), mélasse (3\%), tourteaux $(18 \%)$ et mélange minéral $(1,2 \%)$ à l'auge et la paille dans un râtelier. Le second groupe de taureaux recevait le même concentré d'engraissement dans lequel on avait incorporé la paille à raison de 10 parts pour 100 parts de concentré. Les 2 types de rations ont été distribués ad libitum par ajustements fréquents des quantités distribuées pendant 103 jours. A la fin de la 1ère période, les 2 groupes d'animaux ont été inversés.

Les consommations ont été mesurées individuellement. La digestibilité apparente a été déterminée par collection totale des matières fécales pendant une période de

$\begin{array}{ll}\text { Paille } & \\ \text { Digest. app.(\%) : } & \mathrm{MO} \\ & \mathrm{MA} \\ & \mathrm{FB} \\ \text { Fermentations : } & \mathrm{pH} \\ & \mathrm{AGVT}(\mathrm{mmol} / \mathrm{l}) \\ & \mathrm{NH}_{3}(\mathrm{mgN} / \mathrm{l}) \\ & \text { Glucose }(\mathrm{g} / \mathrm{l})\end{array}$

7 jours. La dégradabilté de la MS dans le rumen a été déterminée sur 6 aliments (paille, orge, maïs, pulpes, tourteaux de soja et lin) par la technique des sachets de nylon. Du jus de rumen a été prélevé toutes les 2 heures pendant 14 heures en vue de déterminer l'évolution du $\mathrm{pH}$ et les paramètres des fermentations.

Les taurillons qui recevaient la paille séparément ont ingéré $8,31 \pm 0,16 \mathrm{~kg}$ de concentré et $1,16 \pm 0,13 \mathrm{~kg}$ de paille. La consommation totale a été de $9,04 \pm 0,11 \mathrm{~kg}$ pour le groupe paille mélangée $(P<0,001)$. La digestibilité apparente a été systématiquement plus élevée lorsque la paille a été mélangée. L'incorporation de la paille hachée dans le mélange a amélioré la dégradabilité des aliments contenant de l'amidon $(P<0,001)$, des fibres à fermentation lente $(P<0,10)$ et de la cellulose $(P>0,20)$. Le $\mathrm{pH}$ a été systématiquement plus élevé chez les taurillons qui avaient reçu la paille hachée indiquant un effet tampon important lié au mode de distribution de la paille. Il en a été de même pour les concentrations en acides gras volatils, ammoniac et glucose.

En conclusion, la distribution de paille hachée en mélange à l'aliment concentré d'engraissement a induit des fermentations plus favorables dans le rumen associées à une amélioration de la digestibilité apparente de la ration.

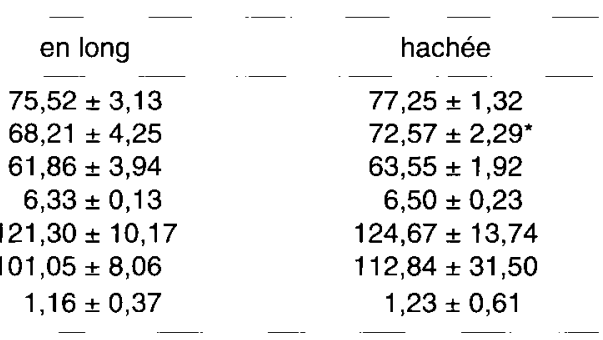

Niveau de signification (*) : $\mathrm{P}<0,05$

Remerciements - Travail réalisé avec la collaboration financière de la Région Wallonne 